\title{
O Projeto Iguaçu de cooperativismo e a formação do cooperativismo do agronegócio: o caso da Cooperativa Agroindustrial Lar
}

\section{The Iguaçu Cooperative Project and the formation of agribusiness cooperatives: the case study of the Cooperativa Agroindustrial Lar}

\author{
Marilucia Bem dos Reis \\ Doutora em Geografia pela Universidade Federal de Santa Maria - UFSM, Brasil \\ luciaben15@hotmail.com \\ Carmen Rejane Flores \\ Docente Titular da Universidade Federal de Santa Maria, Santa Maria - RS, Brasil \\ carmenrejanefw@gmail.com
}

\begin{abstract}
Resumo
O objetivo desse estudo foi analisar a influência do Projeto Iguaçu de Cooperativismo na formação/transformação e desenvolvimento da Cooperativa Agroindustrial Lar no Oeste do Paraná. A metodologia utilizada foi a analise interpretativa, crítica, estruturalista das contradições geradas no sistema cooperativista e as estruturas que se formaram a partir das ações do projeto Iguaçu de cooperativismo no território oestino paranaense. Foram realizados estudos exploratórios e entrevistas para entender como se desenvolveu a implantação desse projeto e seus reflexos na territorialização e na formação da COMASIL atual Cooperativa Agroindustrial Lar. Os resultados apontam que a cooperativa em estudo sob a influência direta do Projeto Iguaçu de Cooperativismo, deixou de ser uma cooperativa mercantil para se transformar em uma cooperativa/ empresa/ comercial/ agroindustrial/ integrada e finalmente formando um Complexo Agroindustrial (CAI) no campo. Isso reforça a ideia de que o cooperativismo do agronegócio no Paraná foi pensado para implantação da modernização da agricultura e consequentemente do CAI no campo. Esse estudo é de grande valia pois ajuda a compreender a complexidade do cooperativismo e sua territorializado no Oeste do Paraná. Apesar de suas limitações, a pesquisa é ponto de partida para outros estudos, além de contribuir para a construção de muitas análises.
\end{abstract}

Palavras-chave: Projeto Iguaçu de Cooperativismo; Complexo Agroindustrial; Oeste do Paraná; Cooperativismo.

\begin{abstract}
This study aimed to analyze the influence of the Iguaçu Cooperative Project on the formation/transformation and development of the Lar Agroindustrial Cooperative in Western Paraná. The methodology used was the interpretive, critical, structuralist analysis of the contradictions generated in the cooperative system and the structures that were formed from the actions of the Iguaçu Project of cooperativism in Paraná's Western territory. Exploratory studies and interviews were carried out to understand how the implementation of this project developed and its effects on the territorialization and formation of the current COMASIL Cooperativa Agroindustrial Lar. The results indicate that the cooperative which is being studied, under the direct influence of the Iguaçu Cooperative Project, ceased to be a mercantile cooperative to become an integrated cooperative/company / commercial/agroindustrial / and finally forming an Agroindustrial Complex (CAI) in the field. It reinforces the idea that agribusiness cooperativism in Paraná was designed to implement the modernization of agriculture and, consequently, CAI in the field. This study is of great value because it helps to understand the complexity of cooperativism and its territorialization in Western Paraná. Despite its limitations, the research is a starting point to other studies, willing to contributing to the construction of many analyzes.
\end{abstract}

Keywords: Iguaçu Cooperative Project; Agroindustrial Complex; West of Paraná; Cooperativism. 


\section{INTRODUÇÃO}

Esse trabalho é um recorte das ações de pesquisa que foram desenvolvidas na tese de doutorado titulada: “A Cooperativa Agroindustrial Lar sob a ótica do território: uma relação híbrida cooperativa/empresa", que se dedicou a analisar a influência do Projeto Iguaçu de Cooperativismo na formação/transformação e desenvolvimento da Cooperativa Agroindustrial Lar no Oeste do Paraná.

A despeito de a modernização da agricultura já estar sendo implantada desde a década de 1950, foi a partir da década de 1970 que as transformações passaram a ser inseridas no âmbito nacional, com a implementação de programas de Estado visando ampliar as áreas de produção inicialmente com a produção de grãos.

O cooperativismo paranaense se desenvolveu a partir das ações do Projeto de Desenvolvimento do Cooperativismo mediante a união de forças entre o Departamento de Assistência ao Cooperativismo (DAC), do Instituto Nacional de Colonização e Reforma Agrária (INCRA) e da Associação de Crédito Rural do Paraná (ACARPA). Foram esses órgãos que, na década de1970 formaram o Projeto Iguaçu de Cooperativismo, projeto que, mais tarde, serviria de modelo para o desenvolvimento do cooperativismo agropecuário no Brasil.

As políticas públicas, desse período, mediante linhas de crédito e projetos como o Projeto Iguaçu de Cooperativismo, criaram cooperativas e investiram em projetos dos cooperados objetivando a implantação de novas técnicas e a diversificação produtiva para o incremento e modernização da agricultura.

Nesse contexto, muitas cooperativas agropecuárias do Oeste do Paraná, se desenvolveram a partir de empresas mercantis que operavam no recebimento e repasse de matérias primas, partindo da integração intersetorial de três elementos básicos: i) as indústrias que produzem para a agricultura, ii) a agricultura moderna e iii) as agroindústrias (GRAZIANO DA SILVA, 1996).

Os anos de 1980 são marcados pelo intenso processo de agroindustrialização das cooperativas no Oeste do Paraná. As cooperativas agropecuárias se tornam cooperativas agroindustriais, atendendo o rural em todas as fases do processo produtivo, integrando as unidades produtivas ao capital financeiro direcionadas pelo Estado mediante políticas públicas específicas.

As cooperativas se transformaram gradativamente em grandes empresas comerciais/industriais/integradas ao agronegócio, que vão se moldando, e ampliando seus territórios e absorvendo às novas exigências. Hoje elas atuam como CAI (Complexo Agroindustrial) no campo, já que o capital industrial comanda a economia rural, adapta as cooperativas segundo seus interesses. 
A Cooperativa em estudo evoluiu juntamente com essas transformações ocorridas no campo. Sua logo marca inicial COMASIL (Cooperativa Mista Agrícola Sipal Ltda), é modificada para COTREFAL (Cooperativa Agropecuária Três Fronteiras Ltda) e por último para Cooperativa Agroindustrial Lar. É nesse contexto que foram examinadas, as questões relacionadas ao cooperativismo do Oeste do Paraná.

\section{O PROJETO IGUAÇU DE COOPERATIVISMO: A BASE DA FORMAÇÃO DOS TERRITÓRIOS DAS COOPERATIVAS DO OESTE DO PARANÁ}

A despeito de terem havido tentativas anteriores de desenvolvimento do cooperativismo, foi apenas na década de 1970 que aconteceu o grande impulso do cooperativismo paranaense. Ele aconteceu a partir da formação do projeto de desenvolvimento do cooperativismo pela união de forças entre o Departamento de Assistência ao Cooperativismo (DAC), o Instituto Nacional de Colonização e Reforma Agrária (INCRA) e a Associação de Crédito Rural do Paraná (ACARPA), com a intenção de criar e desenvolver cooperativas, tomando como exemplo as ações do Projeto Iguaçu de Cooperativismo que era desenvolvido no o oeste e sudoeste do estado do Paraná.

Dessa união, em 1973, se criou em nível nacional, o Projeto Integrado de Desenvolvimento do Cooperativismo (PIDCOOPS). Segundo Lima (s.d, s.p.), ele era, nada menos que: “[...] uma forma de mobilização técnica operacional em favor do cooperativismo, de modo a integrá-lo racionalmente e a organizá-lo em moldes e em escala compatível com as exigências do processo de modernização em âmbito estadual, regional e microrregional”.

Uma das primeiras ações do PIDCOOPS ao organizar o movimento cooperativista foi delimitar o território de responsabilidade de cada cooperativa, evitando competições entre elas. Sua meta inicial foi implantar sete projetos integrados de desenvolvimento cooperativista nos estados de Pernambuco, Sergipe, Minas Gerais, Paraná, Santa Catarina e Rio Grande do Sul.

No estado do Paraná, foram desenvolvidos o Projeto Iguaçu (PIC), o Projeto de Cooperativismo Norte do Paraná (NORCOOP) e o Projeto Centro-Sul de Cooperativismo (SULCOOP). Os projetos continham o mapeamento regional com a estruturação e distribuição das cooperativas no território Paranaense.

Mapear para organizar e orientar a viabilidade econômica de cada cooperativa era o que norteava o projeto. Segundo Lima (1974), os projetos coincidiram com três ondas de colonização que ocorreram no Paraná, como mostra a Tabela 1.

O Projeto Iguaçu de Cooperativismo começou a atuar no Paraná em 1970, apoiando as já existentes 13 cooperativas agrícolas que atuavam na região Oeste e Sudoeste do estado. O Projeto de Cooperativismo Norte do Paraná passou a atuar a partir de 1974, com 22 cooperativas 
agropecuárias na região, e o Projeto Centro-Sul de Cooperativismo em 1976, com 23 cooperativas agropecuárias das regiões Centro e Sul do estado.

Tabela 1- Projetos do Plano Integrado de Desenvolvimento do Cooperativismo no Paraná e suas características.

\begin{tabular}{ccc}
\hline Projeto & Colonização & Características \\
\hline PIC & Colonos do Rio Grande do Sul & Praticavam agricultura de subsistência, plantavam \\
NORCOOP & $\begin{array}{c}\text { Migração do estado de São Paulo } \\
\text { Expansão do plantio do café. }\end{array}$ \\
SULCOOP & $\begin{array}{c}\text { Antigo povoamento de Paranaguá para a a } \\
\text { região central do estado }\end{array}$ & $\begin{array}{c}\text { Criação de gado, indústria de erva-mate e madeireira de } \\
\text { pinho. }\end{array}$ \\
\hline
\end{tabular}

Fonte: (LIMA,1974). Organizado por Marilúcia Ben dos Reis, jul. 2015.

Esses projetos foram se ajustando e adequando a estrutura cooperativista e aos novos patamares pelos quais o setor agrícola vinha passando. Coube a elas levar a modernização às propriedades de seus cooperados e integrá-los ao sistema agroindustrial. Dessa forma, as cooperativas tiveram papel importante na reestruturação produtiva do estado do Paraná.

Os cooperados segundo, Lima (1974), possuíam características próprias, pois se tratavam de colonos migrantes do Rio Grande do Sul que cultivavam cerais e criavam suínos, calcados nos moldes da agricultura de subsistência. Esse cooperados passam dê agricultura de subsistência para uma agricultura moderna que necessitava de pacotes tecnológicos para o seu desenvolvimento.

Para melhor compreender a espacialização dos projetos segue a figura 2 que foi ajustada para destacar o oeste do Paraná. Nela contém as cooperativas do oeste do Paraná com seus respectivos entrepostos.

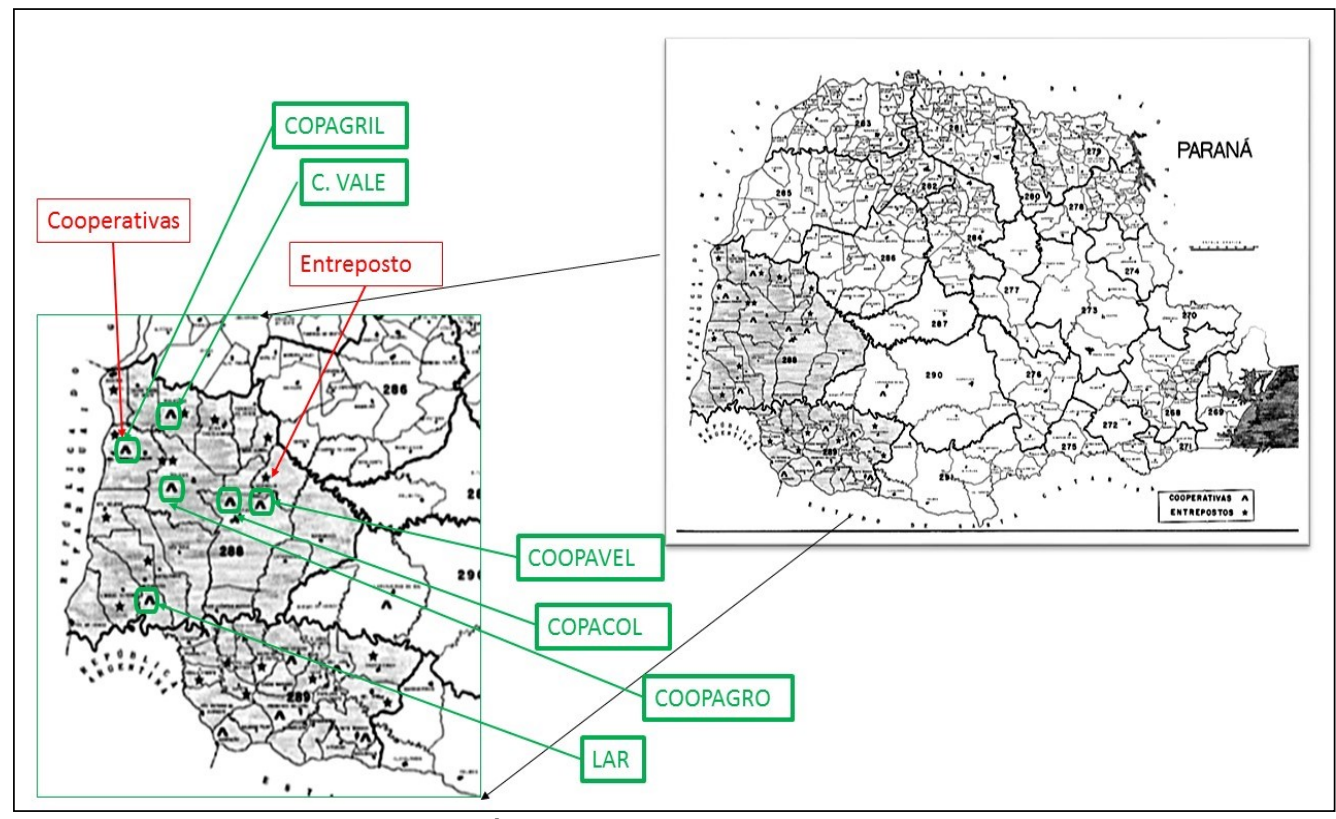

Figura 2 - Área do Projeto Iguaçu Cooperativista.

Fonte: (IPARDES,1975) Organizado por Marilúcia Ben dos Reis, jul. 2015. 
O Projeto Iguaçu que foi o inspirador do desenvolvimento cooperativista era dividido em dois grupos: um na região Oeste e outro na região Sudoeste do estado do Paraná e o integravam: a Cooperativa Agrícola Mista de Palotina Ltda.(CAMPAL - COOPERVALE, atual C. VALE), de Palotina; Cooperativa Mista Agrícola Sipal (COMASIL - COTREFAL e atualmente Lar), de Medianeira; Cooperativa Agrícola Mista Rondon Ltda.(COPAGRIL), Marechal Cândido Rondon; Coopavel Cooperativa Agroindustrial (COOPAVEL), Cascavel; Cooperativa Agropecuária Mista Oeste (COOPAGRO), Toledo; e Cooperativa Agrícola Consolata (COPACOL), Cafelândia, distrito de Cascavel.

Neste trabalho se enfoca apenas as cooperativas da região Oeste. Segundo o Ipardes (1974, até 1970 só haviam três cooperativas no Oeste do Paraná. A Cooperativa Agrícola Mista de Palotina Ltda. (CAMPAL - COOPERVALE, atual C. VALE), a Cooperativa Agrícola Mista Cafelândia (COPACOL), localizada em Cafelândia, distrito de Cascavel, ambas fundadas em 1963, e a Cooperativa Mista Agrícola Sipal (COMASIL - COTREFAL e atualmente LAR), localizada em Missal, distrito de Medianeira, fundada em 1964.

Segundo o IPARDES (1974) dentro do Projeto Iguaçu de Cooperativismo, no ano de 1970, buscando suprir a infraestrutura de armazenamento e beneficiamento da produção e a necessidade de fornecimento de insumos e serviços foram fundadas mais 3 cooperativas no Oeste: a Cooperativa Agrícola Mista Rondon Ltda. - (COPAGRIL), a Cooperativa Agroindustrial de Cascavel (COOPAVEL), a Cooperativa Agropecuária Mista Oeste (COOPAGRO), de Toledo (que anos depois foi incorporada pela Coamo de Campo Mourão). Isso significa dizer que tais cooperativas foram fundadas, já sendo pensadas no CAI.

O IPARDES (1974) registra inclusive que, é a grande produção de soja que se deve o crescimento do cooperativismo na região. As cooperativas foram fundadas pela influência dos órgãos do Estado para desenvolver a modernização da agricultura e implantar o CAI no campo. E logo começaram à construção de armazéns graneleiros para o armazenamento da soja que vinha crescendo na região.

A cultura da soja foi iniciada no Paraná em 1968 sob a atuação de empresas como Sociedade Algodoeira do Nordeste Brasileiro S.A (SANBRA - atual Bunge) e da Sociedade Anônima Moinhos Rio-Grandenses (SAMRIG - atual Bunge). Foi com a soja que as cooperativas se estruturaram e se encaminharam rumo à agroindustrialização para a produção de óleo e do farelo inicialmente.

Bialoskorski Neto (2001) comenta que, partir de 1970 esse produto, amparado pelo Projeto Iguaçu de Cooperativismo e financiado pelo Banco Nacional de Crédito Cooperativo S.A. (BNCC), Banco Regional de Desenvolvimento do Extremo Sul (BRDE) e pelo Banco do Brasil (BB) se tornou o carro-chefe da agricultura empresarial e da agroindústria paranaense e as 
cooperativas passaram a dominar sua produção e comercialização forçando as empresas privadas a perder representatividade.

Superando a falta de infraestrutura de armazenamento da produção e as dificuldades de escoamento da safra que necessitavam ser comercializadas as cooperativas agropecuárias no Brasil passaram por um processo intenso de verticalização e agregação de valor às commodities: "Esses investimentos foram historicamente realizados nas plantas processadoras de soja - com intuito da produção do óleo de soja" (BIALOSKORSKI NETO, 2001, p. 648).

Em 1971, a partir do Projeto Iguaçu de Cooperativismo - PIC, surgiu a Organização das Cooperativas do Estado do Paraná (OCEPAR), que integra a Organização das Cooperativas Brasileiras (OCB), formada por três sociedades distintas: o Sindicato e Organização das Cooperativas do Estado do Paraná (OCEPAR); o Serviço Nacional de Aprendizagem do Cooperativismo (SESCOOP PR); e a Federação e Organização das Cooperativas do Estado do Paraná (FECOOPAR).

A Acarpa-atual Emater/PR -, o Incra e o Dac atualmente são os responsáveis pelo projeto, ficando a cargo da Acarpa parte dos trabalhos de campo, com o assessoramento técnico/administrativo junto às cooperativas e cooperados. O território em que está a Cooperativa Lar ficou a cargo do engenheiro agrônomo Paulo Roberto Durgante Lacerda, extensionista da Acarpa, que, também foi mais tarde presidente da Cooperativa.

De acordo com Setti (2014), no começo dos trabalhos ele realizava palestras e reuniões para amenizar as resistências dos colonos de se associarem. Essas resistências eram sequelas de experiências negativas de cooperativas falidas do Rio Grande do Sul e em Santa Catarina e que de alguma forma, serviram para a reestruturação empresarial em resposta ao Projeto Iguaçu de Cooperativismo. O senhor Paulo foi entrevistado por essa pesquisadora em 3/2/2016, na busca de entender como se desenvolveu a implantação desse projeto e seus reflexos na territorialização e na formação da COMASIL Cooperativa Mista Agrícola Sipal Ltda atual Lar.

Segundo Paulo, "O objetivo do Projeto era organizar os produtores e a produção dos produtores rurais em Cooperativas, fornecendo aos mesmos instrumentos e estrutura para que produzissem mais e melhor" (03 fev. 2016). A partir daí foram ampliadas as lavouras de soja, com apoio dos pacotes que acompanhavam as adesões à cooperativa (maquinários agrícolas, sementes selecionadas, adubação química, venenos, entre outros), mas os problemas ainda eram a carência de armazenamento e escoamento da produção.

A primeira ação do projeto Iguaçu de Cooperativismo em relação à COMASIL, determinado em Assembleia Geral Ordinária, foi que a sede da COMASIL seria transferida de sua sede no distrito de Missal para o município de Medianeira, em área próxima do traçado da BR 277. Segundo afirmou o Extensionista do Projeto Iguaçu (03 fev. 2016): 
[...] houve um impacto grande quando os associados tomaram conhecimento do Projeto, e se deram conta de que a Sede da Cooperativa teria que ser transferida para Medianeira e não ficaria em Missal. Foi explicado a eles que ela passaria a ser uma Cooperativa com uma área de ação que incluiria vários municípios da região, tudo indicando que a escala de produção aumentaria em muito, para que ela tivesse competitividade.

Essa situação, na ocasião, gerou ação contrária à transferência da Sede da Cooperativa e isso ficou evidente nas entrevistas com os pioneiros da Cooperativa em estudo. Os argumentos em relação a transferência estavam voltados a infraestrutura como disse um Cooperado Fundador "A cooperativa foi fundada em Missal e depois o Inácio falou o seguinte, nós não tínhamos energia, não tínhamos asfalto, nós vamos ser obrigados a botar a sede em Medianeira, por causa da energia, por causa do asfalto e essas coisas"(COOPERADO FUNDADOR 1, 08 dez. 2015).

Num primeiro momento, eles não concordaram com a mudança. O asfalto citado e a energia se referem respectivamente a $\mathrm{Br} 277$ que liga o Oeste do Paraná ao Porto de Paranaguá, já pensando no escoamento da produção e a energia elétrica já havia chegado em Medianeira para a implantação da modernização da agricultura, como armazéns graneleiro para receber a produção da soja.

O Cooperado Fundador 1 (08 dez. 2015) justifica a resistência deles afirmando que a preocupação na época girava em relação ao crescimento econômico do então distrito, crescimento que foi afetado por essa transferência. "Nós fomos contra. Nós não queríamos de jeito nenhum. Nós nos reunimos e batemos tudo contra, mas no final ela foi passada para Medianeira e daí surgiu a COTREFAL" (Figura 3).

Mas a transferência de localização da sede se efetivou e as mudanças não se restringiram em mudar a sede da Cooperativa, mas resultaram também em alteração de sua razão social e da sua área de atuação, que de local passou a ser regional atuante nos municípios, Medianeira, Missal, São Miguel do Iguaçu, Santa Terezinha de Itaipu, Itaipulândia, Ramilândia, Diamante do Oeste, Serranópolis e Matelândia, seguindo o princípio secundário da prática opcional do cooperativismo, que determina o regionalismo ou a unicidade do cooperativismo.
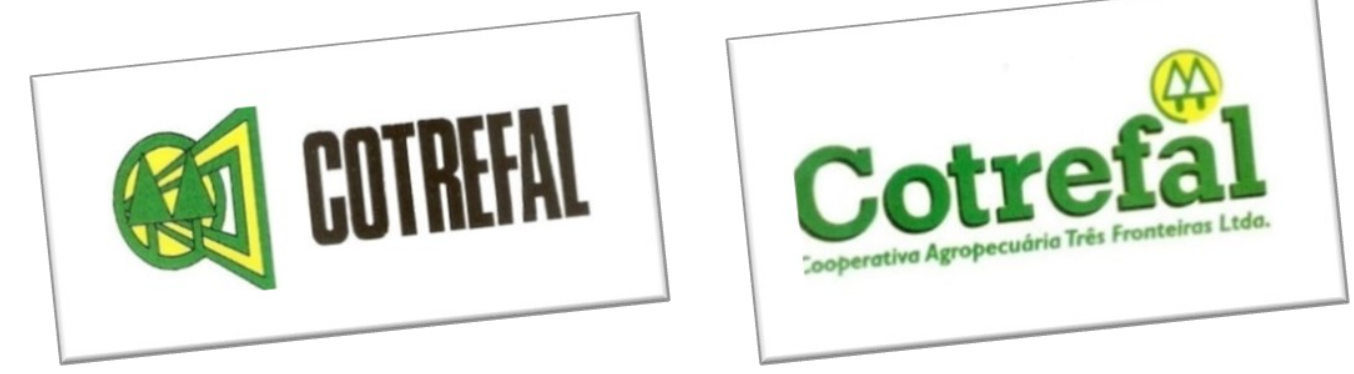

Figura 3 - Mudança da razão social de COMASIL para COTREFAL (1973-1998 e 1998-2001). Fonte: (MARIN, 2005). 
Segundo Setti (2014), na ocasião a logomarca e razão social foram alteradas de COMASIL, de ação local no distrito de Missal como herança da SIPAL Colonizadora, para Cooperativa Agropecuária Três Fronteiras Ltda. (COTREFAL), agora com ação regional e fazendo menção aos três países Brasil, Paraguai e Argentina, que fazem fronteira entre si no extremo da região Sul.

Instalada no município de Medianeira, a COMASIL, então com a nova roupagem de COTREFAL, inicia, em 1972, a construção de armazéns, tanto em Medianeira (a começar do local da sede), quanto em São Miguel do Iguaçu e em Santa Helena. Em 1977 é inaugurado um posto de combustíveis em Medianeira também de propriedade da COTREFAL. Segundo afirmou o Extensionista do Projeto Iguaçu (03 fev. 2016):

Nessa época, no Sul e Centro do Paraná, nas regiões de Guarapuava e Ponta Grossa, já
existiam cooperativas. No Norte, Oeste e Sudoeste eram poucas. Nestas duas últimas,
regiões de colonização mais recente, o desmatamento se aproximava do fim e a destoca das
áreas para a implantação das lavouras mecanizadas avançava rapidamente. Com isso, era
previsível a necessidade de organizar os produtores e, numa primeira etapa, construir
armazéns para receber e armazenar a produção, necessidade que, obviamente, aumentaria
rapidamente nos anos seguintes.

O que antes era "COMASIL" e representava colonos migrantes do Rio Grande do Sul, com características peculiares próprias, passou a implantar um modelo de modernização da agricultura e um CAI que abre mercado além da fronteira nacional. O sistema cooperativista passa a atuar em um mercado bem mais complexo, a montante e a jusante do sistema produtivo, sendo fornecedora de matéria-prima para uma agropecuária que se aproxima cada vez mais do CAI.

Ou seja, em razão do aumento da produtividade, o novo modelo necessitava de infraestrutura e logística para armazenar, beneficiar e transportar a produção. Assim, o sistema cooperativista vai se tornando cada vez mais complexo, a primeira rede de atendimento a essas questões, foram a criação dos entrepostos onde se comercializavam os insumos para as safras e se recebia a produção nos silos graneleiros para armazenar a soja o milho do novo sistema produtivo. $\mathrm{Na}$ sequência o Estado apoiou as iniciativas trazendo para o Oeste sua experiência de armazéns verticais, que já havia sido introduzido nas áreas de café do norte do Paraná (SERRA, 1986).

Com o apoio do Estado, incentivos do BNDE e do Projeto Iguaçu de Cooperativismo as cooperativas passam a crescer com mais velocidade. Segundo o engenheiro Paulo, em 1973 a COTREFAL:

[...] já tinha construído um armazém graneleiro para 250 mil sacos, equipado com moega e secador com capacidade para 40 toneladas, um armazém de fundo chato com capacidade para armazenar 100 mil sacas, balança para 60 toneladas com um pequeno escritório em anexo para o funcionamento da mesma, situado em Medianeira. Um armazém graneleiro com capacidade para 250 mil sacos, equipado com moegas e secador para 40 toneladas, balança para 60 toneladas com escritório em anexo para o seu funcionamento, situado em Santa Helena e um conjunto de moegas para recebimento a granel em São Miguel do Iguaçu (PAULO, EXTENSIONISTA DO PROJETO IGUAÇU, 03 fev. 2016). 
Nesse período a comercialização dos insumos para a produção era realizada pelos técnicos junto às unidades produtivas e no escritório em anexo à balança que recebia produção. Os técnicos são os mediadores a montante e a jusante do processo produtivo. Com atuação em Medianeira sob tutela do Projeto Iguaçu de Cooperativismo e apoio da Acarpa e do INCRA, à medida que a Cooperativa crescia e construía mais armazéns o número de cooperados aumentava e saltou de 1.414 em 1972 para 2.141 em 1973 (SETTI, 2014).

Nessa evolução contaram também com o apoio do Banco do Brasil que, colaborava com a agricultura introduzindo no campo, por meio de ofertas de financiamentos, crédito de custeio agrícola e de capital de giro e a diversificação de culturas, que também servia para evitar a sucessão de produtos na mesma área. Mas o engenheiro entrevistado esclarece que as cooperativas sofriam ao negociar com o Banco do Brasil S. A., pois,

[...] ele exigia, para isso, $60 \%$ de garantia real, hipoteca em primeiro grau, e isso após uma burocracia bastante grande, de bens imóveis, para poder emprestar o dinheiro. Isso era impossível para a Lar, pois tínhamos apenas os terrenos onde seriam construídas as obras, terrenos adquiridos já à duras penas, pois os recursos eram praticamente nulos. Com o BRDE era diferente: ele considerava como garantia real o terreno e as construções que SERIAM construídas, o que mudava tudo e, praticamente, viabilizava o financiamento. Mas, repito, nem tudo foram flores, ele exigia como garantia acessória, notas promissórias assinadas pelos cooperados, cujos valores eram proporcionais às quotas partes que cada associado tinha na cooperativa, de maneira que o agricultor maior assinava um valor maior e o menor um valor menor, o que tornava a operação bastante democrática. (EXTENSIONISTA DO PROJETO IGUAÇU, 03 fev. 2016).

Ele disse também que o Banco Regional de Desenvolvimento do Extremo Sul (BRDE), com sede em Curitiba, era outro órgão público que fornecia subsídios financeiros, mas exclusivamente em investimentos pesados para construções, baseado na viabilidade econômicofinanceira.

Apesar da cooperativa ser beneficiada com créditos oficiais foram os cooperados pioneiros que avalizaram o processo de implementação dos armazéns e toda a infraestrutura necessária para implementação das lavouras, com investimentos em produtos da modernização da agricultura para se introduzir no mercado bem como as instalações agroindustriais da Cooperativa. Era uma via de mão dupla, por meio da qual os cooperados foram gradativamente sendo introduzidos no mercado e se especializaram na produção, direcionada pela territorialização capitalista no campo, acompanhando o perfil estabelecido por esse sistema.

Os cooperados que receberam incentivos para aderirem à modernização e se tornarem agricultores especialistas em determinados cultivos (soja e milho) ou criação de animais (aves e suínos) abandonando definitivamente suas formas tradicionais de trabalhar e produzir. Nessas bases se constituía a organização seguindo a lógica produção agropecuária/ instituições/ indústrias de insumos/ indústrias de processamento/comercialização/consumidor (SZMRECSÀNYI, 1983). 
A despeito do desenvolvimento impetrado no processo de cooperativismo, se faz necessário reafirmar que o Projeto Iguaçu foi o marco da formação do território e da rede do cooperativismo no Oeste do Paraná, e permaneceu na base de apoio intermediando as iniciativas do setor.

A partir de 1970 entrou em cena a moagem de grãos e produção de óleo iniciada pela Cocamar, no Norte paranaense em 1979, e pela Cooperativa COTREFAL (atual Cooperativa Lar), na região Oeste do estado, que passou a produzir óleo a partir da aquisição da massa falida do grupo Ruaro.

A Oleolar S/A, localizada no município de Céu Azul, foi um dos pivôs de aceleração e consolidação/integração do setor primário/secundário/terciário da Cooperativa Lar. Essa unidade tinha capacidade instalada para esmagamento de 1.000 toneladas de soja/dia, para a produção de 9.000 toneladas de farelo e para armazenagem de 5.350.000 litros de óleo bruto (MARIN, 2005). Os recursos para essa aquisição foram captados pelo capital de giro da própria cooperativa, conjuntamente com verbas do BRDE e do Banco Nacional de Crédito Cooperativo S.A. (BNCC).

Derivando dessa atividade houve a formação do "complexo soja" na estrutura da Cooperativa Lar desenvolvendo a produção de insumos para a indústria de ração, acompanhada da produção de milho, o que segundo o Ipardes (2003), criou as bases para a produção e a industrialização de carne de pequenos animais, atividade ligadas às pequenas unidades familiares. Isso modificou a base tradicional de criação de animais para animais em confinamento, tudo arregimentado pela padronização do sistema produtivo, congregando agricultura/indústria/serviços e pesquisa tecnológica.

O cultivo da soja crescia no Paraná. Assim, de 5.000 hectares em 1960 passou para 172.000 em 1969 e, em 1990, a área já compreendia 679.749 hectares cultivados e em 2001 a área foi de 733.114 hectares segundo dados do Ipardes (2003). Segundo o mesmo instituto, cresciam também as atividades de agroindustrialização do farelo, óleo e ração, produtos que, mais tarde, acabaram estabilizando as atividades de suinocultura e de avicultura. Crescia a influência do agronegócio nas unidades produtivas do Oeste do Paraná.

Em 1980, o Paraná já contava com 69 cooperativas agropecuárias, com aproximadamente 107.000 cooperados, o que representava 24\% dos produtores do Estado (ROCHA, 1999). As cooperativas se estruturaram no CAI, passam da condição de repassadores de matérias-primas para um sistema mais complexo, o da agroindustrialização da produção e transporte, atingindo o mercado externo.

Seguindo os parâmetros da economia, as cooperativas passaram a criar unidades de supermercados atuando na área de comercio atacadista e varejista. Em 1983, a Lar instala, no município de Medianeira o Supermercado COTREFAL. No ano seguinte, em Diamante do Oeste, 
em Santa Rosa do Ocoy (distrito de São Miguel do Iguaçu), em Santa Terezinha do Itaipu, em São Miguel do Iguaçu e em Missal. A partir de 1985 inauguraram supermercados em Ramilândia e em Flor da Serra (atual Serranópolis do Iguaçu). Segundo o Relatório e balanço (COOPERATIVA LAR, 2015), atualmente possuem 15 supermercados distribuídos nos municípios do Oeste do Paraná.

As transformações econômicas e de mercado, oriundas da abertura comercial do Brasil e da constituição do Mercosul, levam a COTREFAL a rever algumas de suas estratégias e a discutir seu futuro frente a um novo ambiente competitivo. A cooperativa necessitava fortalecer os cooperados para suprir as demandas da agroindústria, que vinha se consolidando, e a cooperativa de crédito objetivava financiar esse processo, reorganizando o trabalho e a produção nas unidades produtivas.

Assim, em 1985 se constituiu a instituição financeira denominada Cooperativa de Crédito Rural Três Fronteiras Ltda. (CREDIFRONTEIRAS), empreendimento que hoje atua com o nome de Sicredi. Instalada dentro da COTREFAL. Sua função era financiar os produtos do agronegócio dos cooperados que já não tratavam apenas da produção de grão, mas também da atividade de avicultura, de suinocultura e de bovinocultura (gado leiteiro) acompanhado de padrões agroindustriais que demandam recursos.

O cooperativismo de crédito foi muito importante para o processo de agroindustrialização das unidades produtivas do Oeste paranaense. Foi através dele que os pequenos e os médios produtores conseguiram recursos para implantar as atividades do CAI como aves, suínos e leite.

A rede agroindustrial que se formou, foi se configurando pela articulação de distintos agentes sociais: agricultores, indústrias produtoras de insumos e máquinas, indústrias processadoras/beneficiadoras de matéria-prima, indústria de bens de consumo, instituições financeiras, empresas de transporte, empresas comerciais e exportadoras, organismos governamentais, centros de pesquisa e agências de publicidade. O cooperativismo segue os padrões agroindustriais e modifica seu sistema organizacional. A COTREFAL dá finalmente lugar à Cooperativa Agroindustrial Lar.

\section{CONSIDERAÇÕES FINAIS}

O cooperativismo no Oeste paranaense se desenvolveu a partir das ações do Projeto Iguaçu de cooperativismo, resultante da união de forças entre do Departamento de Assistência ao Cooperativismo (DAC), do Instituto Nacional de Colonização e Reforma Agrária (INCRA) e da Associação de Crédito Rural do Paraná (ACARPA) mas, principalmente pela ação dos cooperados. 
Com o intenso processo de agroindustrialização as cooperativas agropecuárias se tornam cooperativas agroindustriais, passando a atender o rural em todas as fases do processo produtivo, a indústria e comércio e ao capital financeiro. O Projeto Iguaçu foi fundamental para a estruturação das cooperativas, em todas suas fases, determinando sua viabilidade econômica.

Ao abarcar novos ramos de negócio, as cooperativas passam de locais para regionais, tornando o processo produtivo cada vez mais complexo. A busca é por eficiência econômica da "empresa" seguindo o processo de verticalização da produção com a implantação das cooperativas centrais para completar a formação dos Complexos Agroindustriais seguindo a mesma política no sentido territorial. As cooperativas centrais congregam a agroindustrialização de várias cooperativas para formarem os complexos de aves, suínos e leite principalmente, viabilizando assim suas atividades.

No caso em questão, a Cooperativa Lar que se chamava COMASIL passou de local para regional atuando não mais em Missal, mais em Medianeira, de onde, com o nome de COTREFAL se espraiou para todo o oeste do Paraná, para o país e para o mundo, ampliando as atividades produtivas com a construção silos para o recebimento de grão e agroindustrialição da atividades de aves, suínos e gado leiteiro.

Foram transformações profundas saindo da produção de subsistência para o modo de produção cooperativista, calcadas na ressignificação do cooperativismo que atualmente já se aproxima da lógica empresarial e se afasta dos princípios cooperativistas. O que começou como um projeto de desenvolvimento agrícola sob a responsabilidade do Projeto Iguaçu de Cooperativismo galgou fronteiras e hoje se apresenta como um marco significativo a atuar em todos os setores da economia do Paraná e diante do mercado internacional.

\section{REFERÊNCIAS}

BIALOSKORSKI NETO, S. Cooperativas: economia crescimento e estrutura de capital. 1. ed. São Paulo: OCESP/SESCOOP-SP, 2001. 178p.

COOPERATIVA AGROINDUSTRIAL LAR. História. S.d. Disponível em: $<$ http://www.lar.ind.br/v4/institucional/index.php>. Acesso em: 12 mai. 2015.

IPARDES, INCRA. Análise sócio econômica do Projeto Iguaçu de Cooperativismo (PIC), das regiões oeste e sudoeste do Paraná. Curitiba, 1974-1975.

Instituto Paranaense de Desenvolvimento Econômico e Social. Leituras regionais: Mesorregião Geográfica Oeste Paranaense. 1. ed. Curitiba: IPARDES, 2003. 143p.

Instituto Paranaense de Desenvolvimento Econômico e Social. Cooperativas de produção agropecuária do estado do Paraná: diagnóstico e análise. Curitiba, julho de 1974. 
LIMA, L. M. História do cooperativismo no Paraná. Revista Paranaense de Desenvolvimento, $n$. 43, p. 39-66, 1974.

MARIN, R. Lar na história: os 40 anos da Cooperativa Agroindustrial Lar. 1. ed. Cascavel: Gráfica Tuicial, 2005. 200p.

ROCHA, E. E. R. B. O cooperativismo agrícola em transição: dilemas e perspectivas. 1999. 236 f. Tese (Doutorado em Ciências Econômicas) - Instituto de Economia, Universidade Estadual de Campinas, Caminas, 1999.

SETTI, E. Uma história de cooperação, atitude e amor: Lar 50 anos. 1. ed. Medianeira: Cooperativa Agroindustrial Lar, 2014. 40p.

SZMRECSANYI, T. Nota sobre o complexo agroindustrial e a industrialização da agricultura no Brasil. Revista de Economia Política, São Paulo, v. 3, n. 2, p. 141-144, 1983.

\section{ENTREVISTAS:}

Extensionista que implantou Projeto Iguaçu de Cooperativismo na Cooperativa Lar:

LACERDA, Paulo Roberto Durgante, 03 fev. 2016. Citação: (Extensionista do Projeto Iguaçu, 03 fev. 2016)

Cooperados fundadores da Cooperativa Lar:

RECK, Silvini. Entrevista concedida a Marilucia Ben dos Reis. Missal, 08 dez. 2015. Citação: (Cooperado Fundador 1, 08 dez. 2015). 